\title{
REMOVAL OF Cr (VI) FROM AQUEOUS SOLUTION BY ADSORPTION ON THE NATURAL AND ACTIVATED FLUORAPATITE
}

\author{
R. El Kaim Billah ${ }^{1, *}$, Y. Elyamani, ${ }^{2,3}$, Y. Rakhila ${ }^{3}$, M. Agunaou ${ }^{1}$ \\ and A. Soufiane ${ }^{1}$ \\ ${ }^{1}$ Department of Chemistry, University of Chouaib Doukkali, Faculty of Sciences, Laboratory of \\ Coordination and Analytical Chemistry , Avenue Jabran Khalil Jabran B.P 299-24000, \\ (El Jadida) Morocco. \\ ${ }^{2}$ Department of Chemistry, University of Hassan II-Casablanca, Faculty of Sciences, Ben M'Sik, \\ Laboratory of Chemistry-Physic Catalysis \& Environment, Avenue Driss El Harti B.P 7955, Sidi \\ Othmane, (Casablanca) Morocco. \\ ${ }^{3}$ Department of Chemistry, University of Hassan II-Casablanca, Faculty of Sciences and \\ Techniques, Laboratory of Physical Chemistry \& Bioorganic, BP. 146,(Mohammedia) Morocco. \\ *E-mail : rachidelkaimbillah@gmail.com
}

\begin{abstract}
The present paper to study the immobilization of chromium ions $\mathrm{Cr}$ (VI) in an aqueous solution by adsorption on a natural phosphate $(\mathrm{PN})$ and activated (PA).The natural phosphate whose main component is fluorapatite $\mathrm{Ca}_{10}\left(\mathrm{PO}_{4}\right)_{6} \mathrm{~F}_{2}$. The study of the retention of chromium (VI) ions on natural and activated flourapatite is conditioned by several parameters namely the $\mathrm{pH}$. The initial concentration of metals and the contact time. Results obtained showed that after 40 minutes of contact. The results obtained showed that after 40 minutes of contact, the elimination of chromium (VI) was maximum with a yield of $67.4 \%$ for the natural flouraptite and $75.9 \%$ for the activated phosphate. Increasing the adsorbent dose $(0.5$ to $1 \mathrm{~g} / \mathrm{l})$ makes it possible to improve the chromium removal efficiency with an initial concentration $(10 \mathrm{mg} / \mathrm{l}) / 1$. The efficiency of removing chromium (VI) by each adsorbent decreases with the increases of the initial chromium content (2 to $10 \mathrm{mg} / \mathrm{l})$. $\mathrm{PH}$ has a significant effect on the retention rate of chromium (VI). The efficiency of removing $\mathrm{Cr}$ (VI) is interesting for acid $\mathrm{pH}$. Moreover, the adsorption of this compound we described by the kinetic models of Langmuir and Freundlich.
\end{abstract}

Keywords: Fluorapatite, Activated phosphate, Adsorption, Chromium, Models Langmuir and Freundlich.

(C) RASĀYAN. All rights reserved

\section{INTRODUCTION}

Chromium is one of the most widely used metals in the industry due to the strength, hardness and corrosion resistance that characterize it. Hexagonal equivalence of chromium is one of the most toxic pollutants due to its carcinogenic properties in humans ${ }^{1}$. Anions corresponding to chromium; $\mathrm{CrO}_{4}{ }^{2-}$ chromates and $\mathrm{Cr}_{2} \mathrm{O}_{7}^{2-}$ dichromate are very mobile in the soil and very soluble in aquatic systems.

Many natural Sorbents were used to remove Cr (VI) ions, such as clays ${ }^{2}$, chitosan $^{3}$, silica ${ }^{4}$, zeolite ${ }^{5}$,

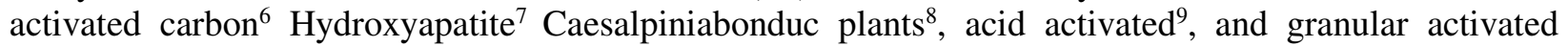
charcoal $^{10}$.

Adsorption identified as an effective way to reduce metal contamination in surface water and industrial waste. The different methods used for the removal of metal cations present in water are electroplating, reverse osmosis, lime treatment, ion exchange. However, a special privilege has been granted in recent years to the use of products of natural origin, such as Phosphate, as they are more abundant and effective an adsorbent.

Rasayan J. Chem., 12(1), 347-354(2019)

http://dx.doi.org/10.31788/RJC.2019.1215078

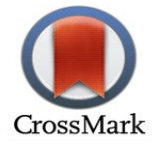


The sedimentary deposits of natural phosphates are composed mainly of apatite of the general formula: $\mathrm{M}_{10}\left(\mathrm{ZO}_{4}\right)_{6} \mathrm{X}_{2}$ with the most common cations: $\mathrm{M}=\mathrm{Ca}, \mathrm{Sr} \ldots \mathrm{Z}=\mathrm{P}, \mathrm{As}, \mathrm{Si} \ldots \mathrm{X}=\mathrm{F}, \mathrm{OH}, \mathrm{Cl} \ldots$ They are represented mainly by the fluorapatite-hydroxylated poles $\left[\mathrm{Ca}_{5}\left(\mathrm{PO}_{4}\right)_{3}(\mathrm{OH}, \mathrm{F})\right]$ and / or the carbonate fluorapatite (called francolite) $\left[\mathrm{Ca}_{5}\left(\mathrm{PO}_{4}, \mathrm{CO}_{3}, \mathrm{OH}\right)_{3}(\mathrm{OH}, \mathrm{F})\right]$. In recent years phosphates have been widely used thanks to their high capacity to immobilize various heavy metals such as $\mathrm{Cd}^{2+}, \mathrm{Pb}^{2+}, \mathrm{Zn}^{2+11}$

The objective of our study is to test the efficiency of removing chromium (VI) dissolved in synthetic solutions by adsorption on the raw and activated fluoroapatite. The purpose of this work is to evaluate this product, which is in abundance in the Khouribga-Morocco region.

\section{Reagents}

\section{EXPERIMENTAL}

The products $\mathrm{K}_{2} \mathrm{Cr}_{2} \mathrm{O}_{7}, \mathrm{NH}_{4} \mathrm{OH}, \mathrm{H}_{2} \mathrm{SO}_{4}, \mathrm{CH}_{3} \mathrm{OOH}, \mathrm{NaOH}$ and $\mathrm{HCl}$ obtained from Sigma-Aldrich. $\mathrm{NaOH}$ and $\mathrm{HCl}$ solutions used to adjust the $\mathrm{pH}$ and diphenylcarbazide was used to complex the residual amount of $\mathrm{Cr}(\mathrm{VI})$.

\section{Preparation of Activated Apatite}

A mass of $20 \mathrm{~g}$ of Khouribga natural phosphate introduced into a $(500 \mathrm{ml})$ flask. The dissolution reaction of the ore carried out by adding a volume of $(250 \mathrm{ml})$ of the water distilled at $\left(75^{\circ} \mathrm{C}\right)$. For $3 \mathrm{~h}$, and then dried overnight at $\left(100^{\circ} \mathrm{C}\right)$. Then activated with $(15 \mathrm{ml})$ of water. Concentrated nitric acid solution $\mathrm{HNO}_{3}$ $(65 \%)$. The reaction mixture kept under continuous stirring using a magnetic stirrer for an optimum period of 2 hours at room temperature. The precipitate is filtered under vacuum, washed with distilled water and then dried in an oven (at $100^{\circ} \mathrm{C}$ for 24 hours) and is finally ,ground to obtain nanoapatites with a size of fewer than $80 \mu \mathrm{m}$.

\section{Adsorption Experiments}

The adsorption experiments we carried out in beakers containing natural apatite as adsorbent and (50 ml) of $\mathrm{Cr}$ (VI) solutions with different concentrations (2, 4, 6, 8 and $10 \mathrm{mg} / \mathrm{l})$ with stirring at (300 rpm) at atmospheric pressure and a $\mathrm{pH}$ (1-7). Was analyzed by UV / VIS spectrophotometer at $540 \mathrm{~nm}$.

The removal percentage of $\mathrm{Cr}(\mathrm{VI})$ ions percentage and the adsorption capacity $\mathrm{q}_{\mathrm{e}}$, we calculated using the following equations.

Adsorption Capacity (mg/g):

$$
\begin{aligned}
& q_{a}=\frac{C_{0}-C_{e}}{m} \cdot V \\
& \%=\frac{C_{0}-C_{e}}{C_{0}} \times 100
\end{aligned}
$$

The removal percentage of fluonae ions witn:

$\mathrm{q}_{\mathrm{a}}$ : Adsorption capacity $(\mathrm{mg} / \mathrm{g})$.

$\mathrm{C}_{0}$ : Initial concentration of the chromium ion solution $(\mathrm{mg} / \mathrm{L})$.

$\mathrm{C}_{\mathrm{e}}$ : Equilibrium concentration of the chromium ion solution $(\mathrm{mg} / \mathrm{L})$.

$\mathrm{m}$ : Adsorbent dose (mg).

$\mathrm{V}$ : Volume of the chromium ion solution (L).

\section{Characterization by (ICP-AES)}

\section{RESULTS AND DISCUSSION}

Table-1shows the chemical analyzes by ICP-AES: inductively coupled plasma atomic emission spectrometry and by DUMAS: method of molecular weight determination (for $\mathrm{CO} 2$ and $\mathrm{F}$ ) of the phosphate studied. (Table 1) show a high content of $\mathrm{Ca}, \mathrm{P}$, and $\mathrm{F}$ indicating the presence of Fluorapatite [Ca10 (PO4) 6(F)2] as a major mineral in Khouribga phosphates.

\section{Characterization by XRD}

A material used in this study was also characterized by X-ray diffraction analysis (Diffractometer Bruker D8 Advanced) using Copper K $\alpha$ radiation $(\lambda=1.5406)$. Figure-1 shows that the majority phase evidenced 
RASĀYAN J. Chem.

Vol. 12 | No. 1 |347 - 354| January - March | 2019

in the natural phosphate studied is fluorapatite $\left(\mathrm{Ca}_{5}\left(\mathrm{PO}_{4}\right)_{5} \mathrm{~F}\right)$. Other secondary phases are also present and attributed to $\mathrm{SiO}_{2}$ quartz.

Table-1: Chemical Composition of Khouribga Gross and Active Apatite

\begin{tabular}{l|l|l|l|l|l|l|l|l|l|l|l}
\hline $\begin{array}{l}\text { Chemical } \\
\text { Composition }\end{array}$ & $\mathrm{P}_{2} \mathrm{O}_{5}$ & $\mathrm{CaO}$ & $\mathrm{SiO}_{2}$ & $\mathrm{~K}_{2} \mathrm{O}$ & $\mathrm{Fe}_{2} \mathrm{O}_{3}$ & $\mathrm{Al}_{2} \mathrm{O}_{3}$ & $\mathrm{~F}$ & $\mathrm{CO}_{2}$ & $\mathrm{SO}_{3}$ & $\mathrm{NaO}_{2}$ & $\mathrm{MgO}$ \\
\hline Natural Phosphate & 32.08 & 52.14 & 3.506 & 0.113 & 0.4 & 0.431 & 3.75 & 5.08 & 4.3 & 0.112 & 0.319 \\
\hline Activated Phosphate & 32.32 & 52.50 & 2.62 & 0.095 & 0.25 & 0.319 & 2.45 & 3.21 & 3.02 & 0.81 & 0.094 \\
\hline
\end{tabular}

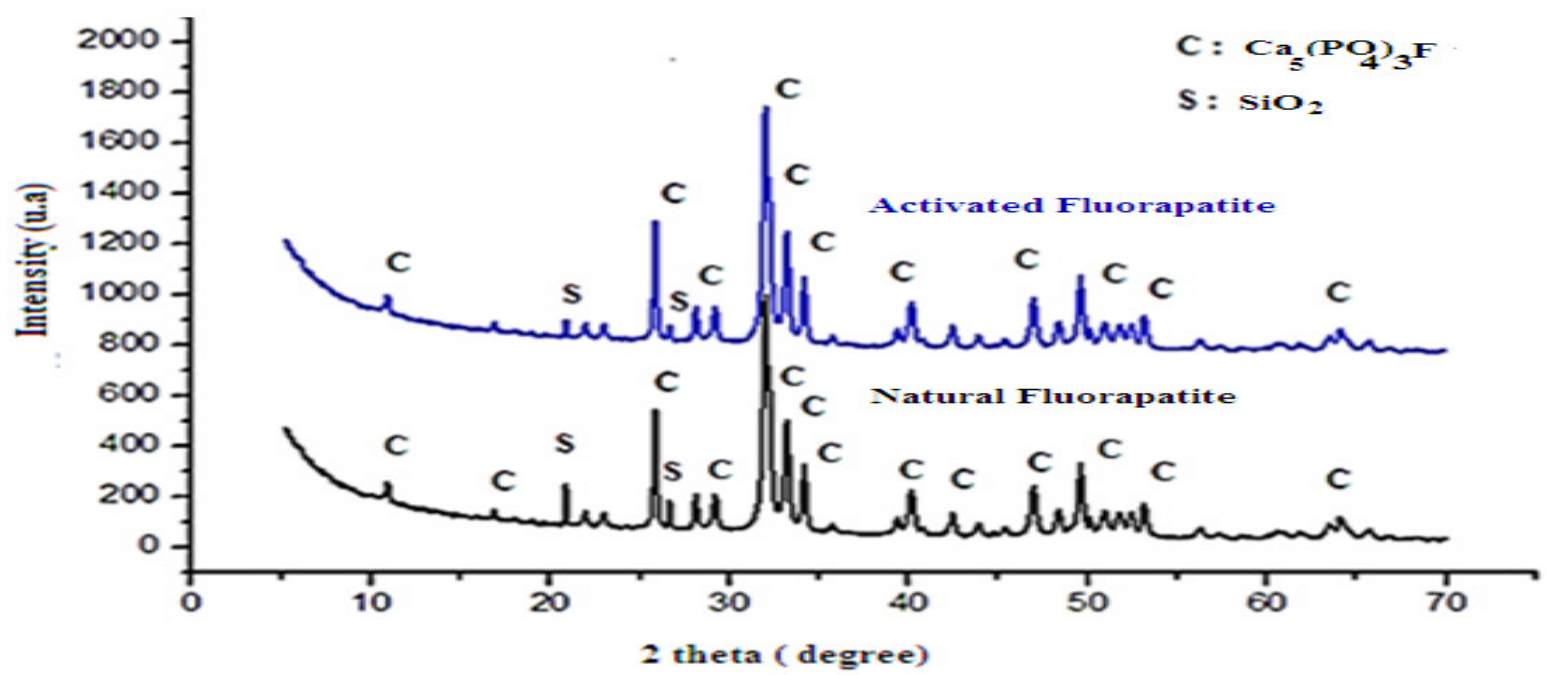

Fig.-1: Diffraction Spectrum of the X-ray of Natural and Activated Fluorapatite

\section{Characterization by FTIR}

The infrared spectroscopy analyses were carried out by a Shimadzu FTIR-8400S apparatus. The dispersion used is potassium bromide. Figure 2 corresponds to the IR absorption spectrum of the activated and raw fluorapatite respectively, of Khouribga used in this study show that two adsorption domains located between $\left(1000\right.$ and $\left.1120 \mathrm{~cm}^{-1}\right)$. Characterize the absorption bands of $\mathrm{PO}_{4}{ }^{3-}$ ions and between (560 and $\left.620 \mathrm{~cm}^{-1}\right)$. The first corresponds to the symmetrical and antisymmetric vibrations $\mathrm{P}-\mathrm{O}$ and the second to the vibrations of the strain OP-O. The bands located at about 1460-1420 and $865 \mathrm{~cm}^{-1}$. associated with $\mathrm{CO}_{3}{ }^{2-}$ group. The bands around $\left(3500 \mathrm{~cm}^{-1}\right)$ would be due to $\mathrm{OH}^{-}$surface groups. We also note that carbonate-related vibration bands are lacking in Activated Fluorapatite. These results proved to be in good agreement with that those obtained for other natural phosphocalcicapatites ${ }^{12,13}$.

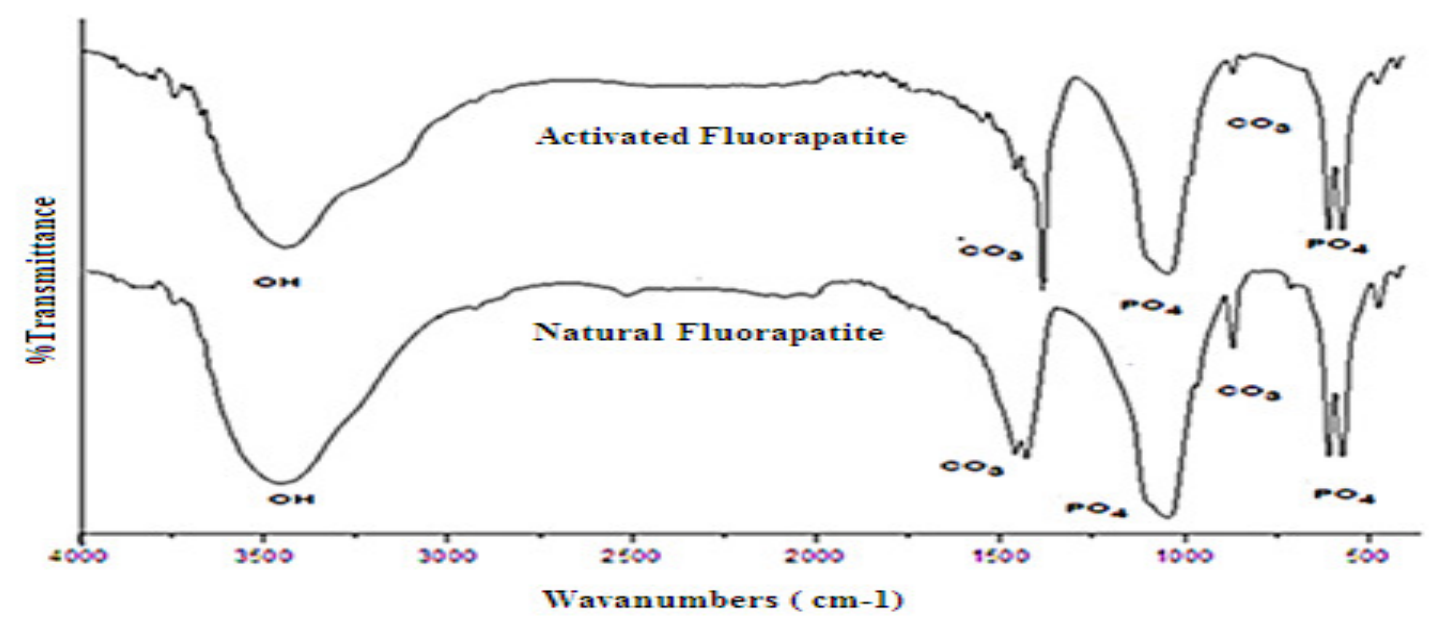

Fig.-2: Infrared Spectrum of Naturel and Activated Fluorapatite. 
RASĀYAN J. Chem.

Vol. 12 | No. 1 |347 - 354| January - March | 2019

\section{Effect of Adsorbent Mass}

The effect of adsorbent mass carried out by placing ( 0.1 to $1 \mathrm{~g}$ ) of adsorbent in a volume of (50 $\mathrm{ml})$ of $\mathrm{Cr}$ (VI) concentration $(10 \mathrm{mg} / \mathrm{L}), \mathrm{pH}(2.08)$. The solutions stirred at a speed of $300 \mathrm{rpm}$ for 1 hour and at a temperature $\left(25^{\circ} \mathrm{C}\right)$. The curve (Figure 3 ) shows that the amount of chromium $(\mathrm{Cr}(\mathrm{VI}))$ adsorbed by the two adsorbents used during this equilibrium study is all the more important. that the quantity used of the adsorbent is high. Explained by of active sites of the adsorbent material. Which can bind chromium $(\mathrm{Cr})$ ions. These increases with the increase in the dose of the natural and activated apatite. Beyond $(0.5 \mathrm{~g} / \mathrm{l})$ we can see that the residual chromium (VI) content remains practically stable.

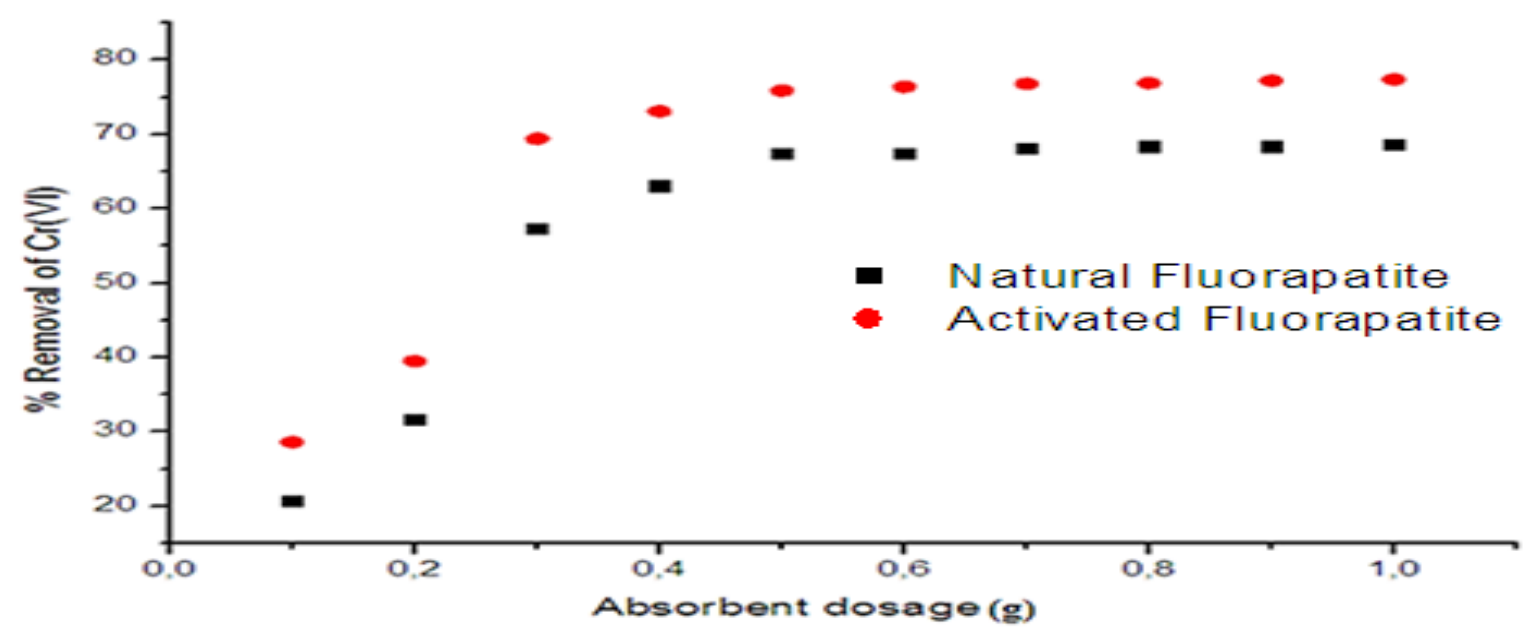

\section{Effect of PH}

Fig.-3: Effect of Adsorbent dose on Chromium ion removal Cr (VI).

We studied the effect of $\mathrm{pH}$ on adsorption $\mathrm{Cr}(\mathrm{VI})$ by adjusting the $\mathrm{pH}$ with $(1 \mathrm{~mol} / \mathrm{L}) \mathrm{NaOH}$ or $(1 \mathrm{~mol} / \mathrm{L})$ $\mathrm{HCl}$ using a $\mathrm{pH}$ meter (EUTECH pH 700) at $\mathrm{pH}$ from 1.0 to 7.0. Using $0.5 \mathrm{~g}$ of adsorbents in $50 \mathrm{ml}$ of $\mathrm{Cr}$ (VI) solution $(10 \mathrm{mg} / \mathrm{l})$ stirring at $(300 \mathrm{rpm})$ and at room temperature for one hour. The results (Figure 4) show the effect of $\mathrm{pH}$ on adsorption $\mathrm{Cr}(\mathrm{VI})$. We can see that the best removal efficiencies obtained in acidic media. At low values of $\mathrm{pH}(2-4)$. The dominant form of $\mathrm{Cr}$ (VI) is $\mathrm{HCrO}_{4}{ }^{-}$while the surface of the adsorbent is positively charged. The increase in $\mathrm{Cr}(\mathrm{VI})$ adsorption is due to the electrostatic attraction between the positively charged adsorbent surface groups ${ }^{14}$ and $\mathrm{HCrO}_{4}$. Which predominate at a value lower than $\mathrm{pH}=3$.

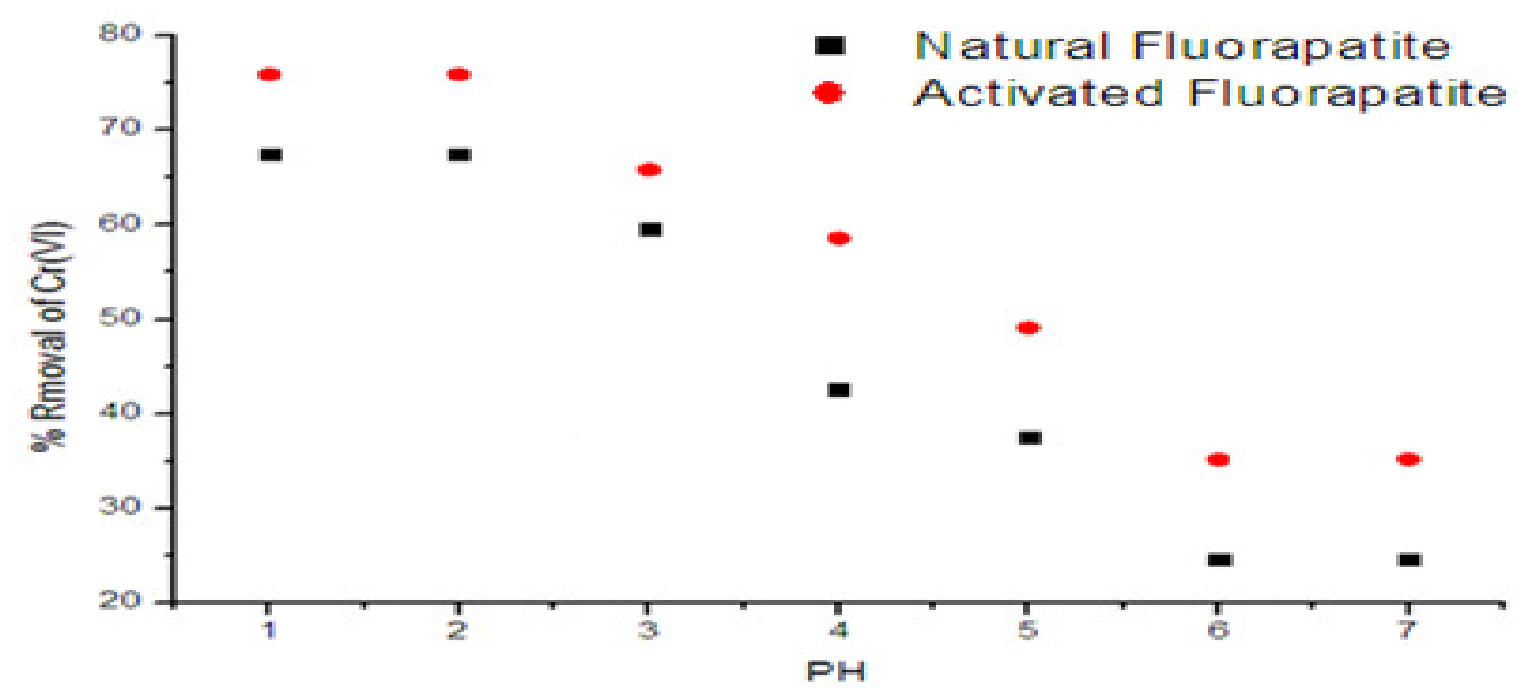

Fig.-4: Effect of $\mathrm{pH}$ on the removal of Chromium ions $\mathrm{Cr}$ (VI). 
RASĀYAN J. Chem.

Vol. 12 | No. 1 |347 - 354| January - March | 2019

\section{Effect of Contact Time}

The Effect of Contact time studies, we carried out at room temperature $\left(25^{\circ} \mathrm{C}\right)$. A stirring speed of 300 rpm. The initial $\mathrm{pH}$ was two for the $\mathrm{Cr}(\mathrm{VI})$ solution. and the mass of the adsorbent is $0.5 \mathrm{~g}$. The measurements made at different contact times (from $5 \mathrm{~min}$ to $90 \mathrm{~min}$ ). As shown in Fig.-5. The elimination yields of the two compounds increase with the stirring times of the solutions. That a plateau appears after a lapse of time. Characterizing the maximum retention of the Chromiums. Indeed. The maximum yield of elimination of the chromium corresponding to this time (40 min) is $(67.4 \%$ ) for the natural phosphate and $(75.9 \%)$ for Activated.

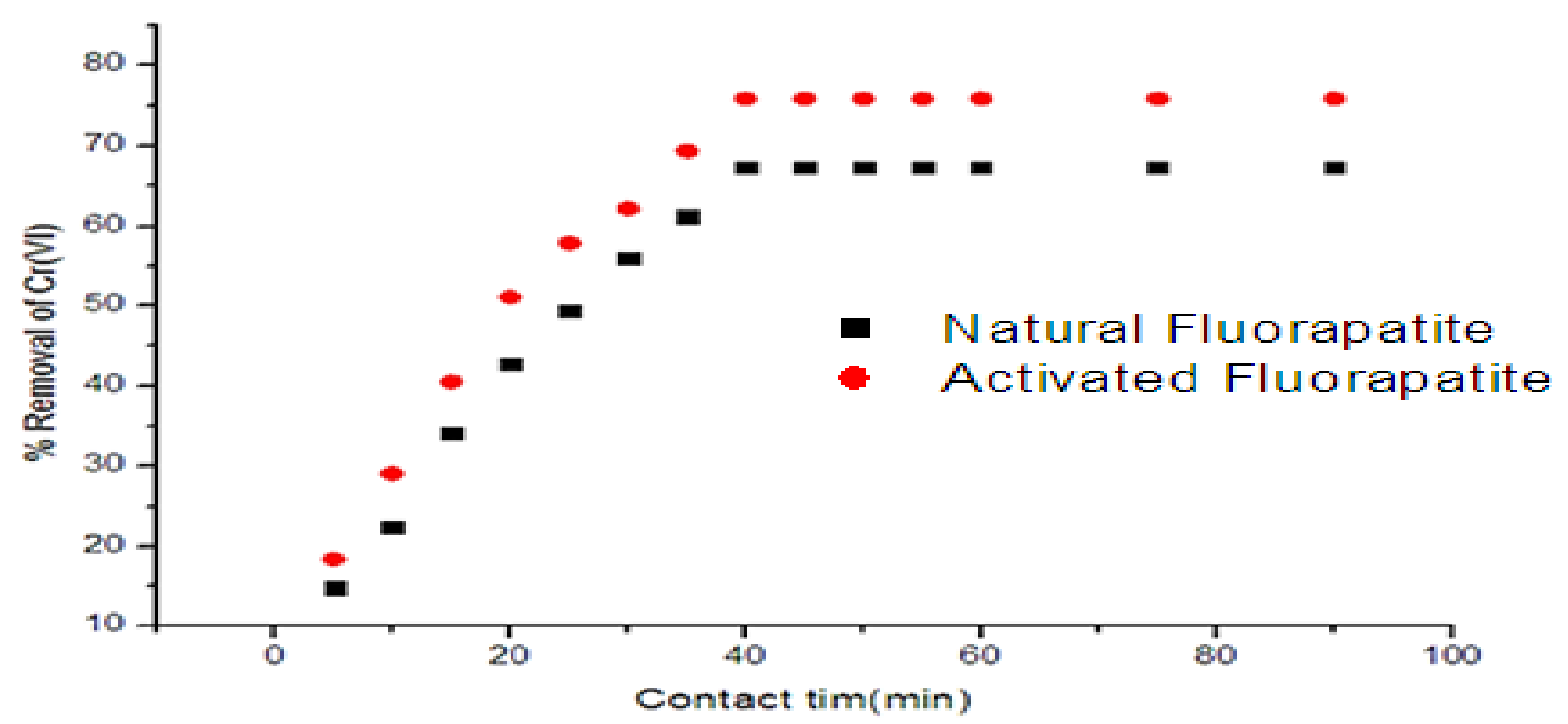

\section{Effect of Initial Concentration}

Fig.-5: Effect of time on the removal of Chromium ions $\mathrm{Cr}$ (VI).

The initial concentration effect of metal ions on adsorption was performed from $(0.5 \mathrm{~g})$ of adsorbent in a volume of $(50 \mathrm{ml})$ of metal ions at concentrations ranging from (2 to $10 \mathrm{mg} / \mathrm{l})$ at a $\mathrm{pH}$. The mixture was made at $\left(25^{\circ} \mathrm{C}\right)$ with stirring at $300 \mathrm{rpm}$ and $\left(25^{\circ} \mathrm{C}\right)$ for 1 hour. Figure- 6 shows that Chrome's removal efficiency decreases with increasing initial Chrome content. This leads to assuming that phosphate adsorption site they saturated by increasing the initial chromium content.

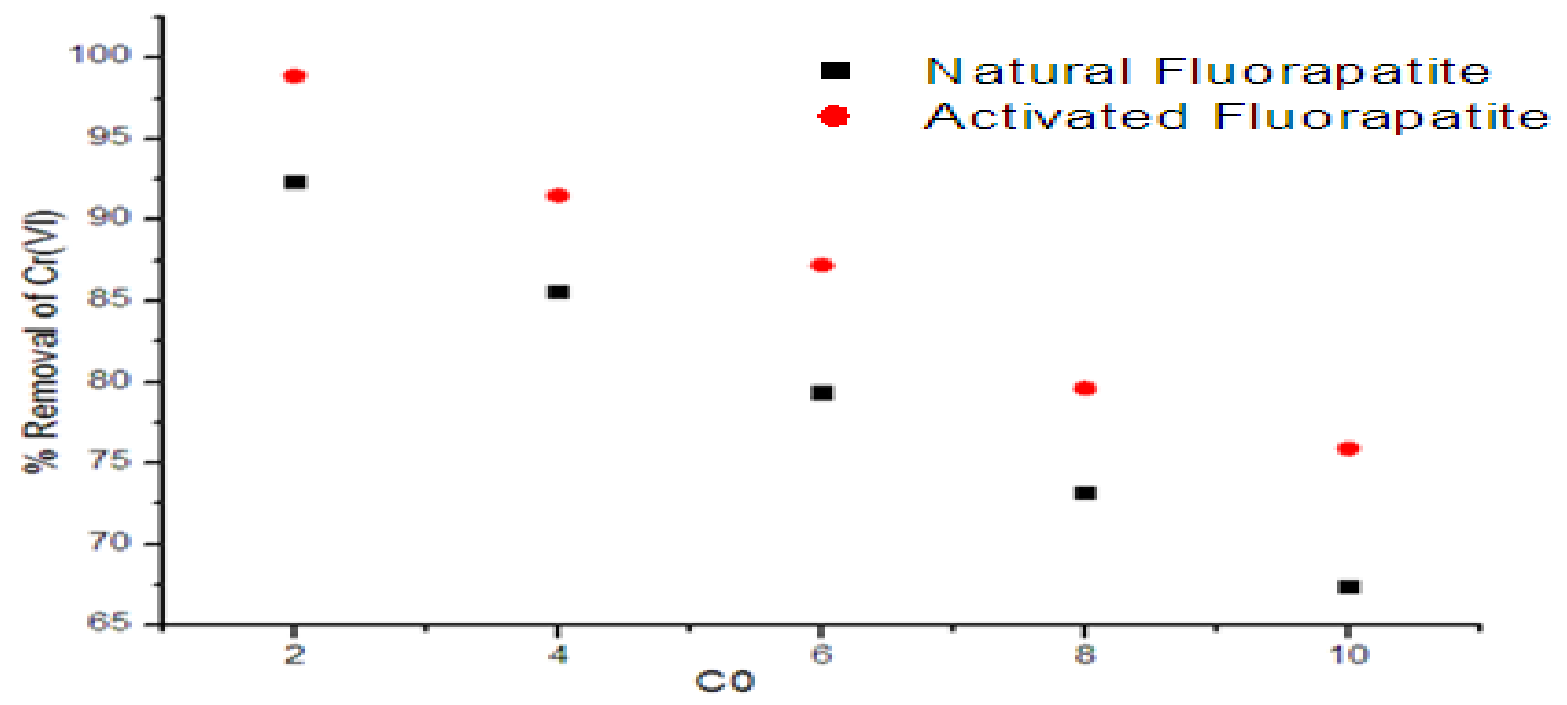

Fig.-6: Effect of Initial Concentration on the Removal Cr (VI) by Natural and Activated Fluorapatite. 


\section{Adsorption Isotherm \\ Langmuir Isotherm ${ }^{15}$}

The Langmuir model developed by equation (3) assumes that a monomolecular layer formed during adsorption without interaction between the adsorbed molecules. This isotherm linearized. Without modification of the equation. it is possible to draw the curve Ce/qe according to Ce. The slope corresponds to $1 / \mathrm{qm}$. The values of $\mathrm{qm}$ and $\mathrm{K}_{\mathrm{L}}$ are calculated and listed in Table-2.

$$
1 / \mathrm{qe}=1 / \mathrm{qm}+1 / \mathrm{qmK} \mathrm{L}_{\mathrm{Le}}
$$

Table-2 shows that the correlation coefficient $\mathrm{R} 2(\mathrm{R} 2=0.99)$ in the Langmuir model is very close to 1 for raw and active apatite. This good correlation between the adsorption data and the Langmuir model indicates the homogeneous nature of the surface of the raw and activated fluorapatite.

The affinity between Adsorbent and Adsorbate determined by the ratio $\mathrm{R}_{\mathrm{L}}$. The latter is a unit less quantity indicating whether the adsorption is all the more favorable when $\mathrm{R}_{\mathrm{L}}$ tends to zero and the more unfavorable that $\mathrm{R}_{\mathrm{L}}$ tends to (1) ${ }^{16}$. The ratio calculated according to the Langmuir constant and the values of the initial concentrations as shown below (eq.4).

$$
\mathrm{R}_{\mathrm{L}}=1 /\left(1+\mathrm{K}_{\mathrm{L}} \mathrm{C}_{0}\right)
$$

$\mathrm{R}_{\mathrm{L}}$ : Report indicates adsorption quality

$\mathrm{K}_{\mathrm{L}}$ : Langmuir constants thermodynamics in equilibrium

$\mathrm{C}_{0}$ : The initial concentration of the solution

The calculated value of $R_{L}$ is (0.07) for crude apatite and (0.05) for activated apatite, indicating that adsorption is favorable for both raw and Activated apatite.

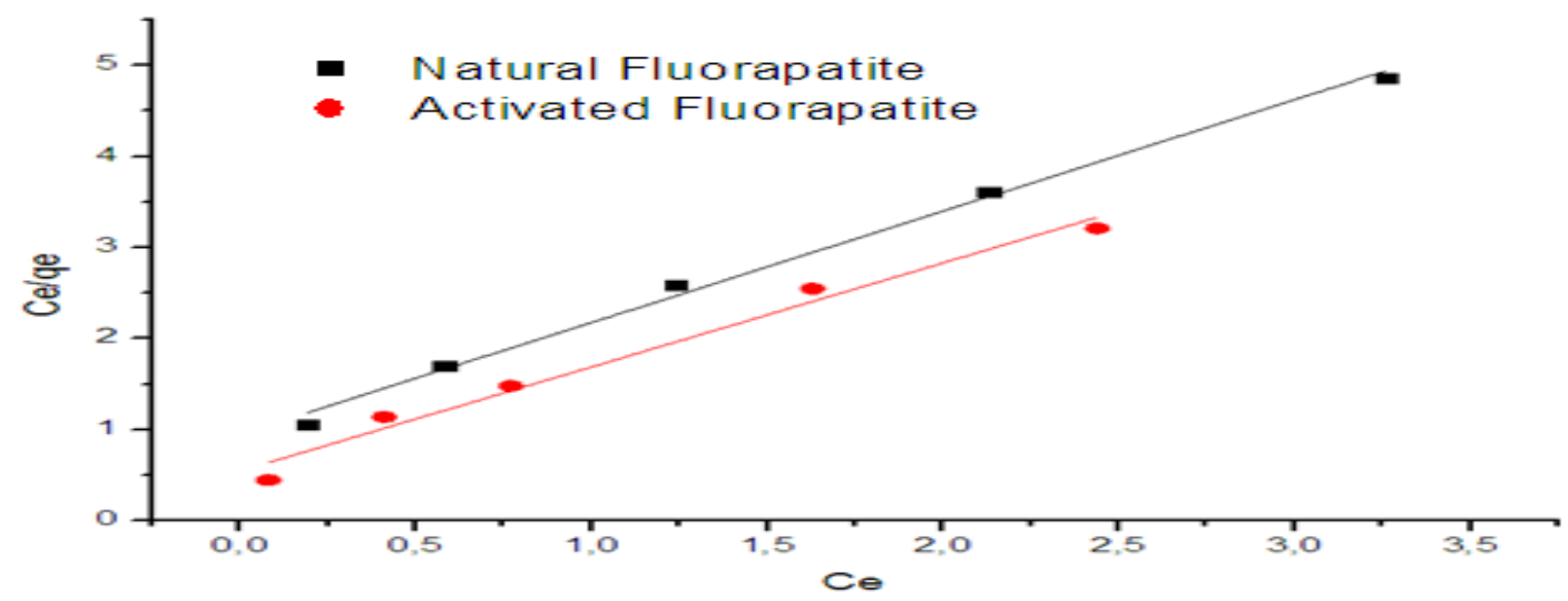

Fig.-7: Linear Representations of the Langmuir Model for the Adsorption of Cr(VI) ions on Natural and Activated

Freundlich Isotherm ${ }^{17}$

Fluorapatite.

Freundlich model after linearization. determined by the following equation:

Lnqe $=\mathrm{LnkF}+1 / \mathrm{nLnCe}$

The graphical representation of $\ln (\mathrm{qe})$ as a function of $\ln (\mathrm{Ce})$ for the raw apatite and the activated apatite is a straight line of direction coefficient $(1 / n)$ and intercept $Y n\left(K_{f}\right)($ Fig.-8). The value $1 / n$ gives an indication of the validity of the adsorption. Value of $1 / \mathrm{n}$ between zero and one indicates favorable adsorption. Values of $\mathrm{K}_{\mathrm{f}}$ and $(1 / \mathrm{n})$ calculated respectively. From the intersection with the intercept and the slope of the straight line for natural and activated apatite they showed in Table-2. Value of $(1 / n=0.41)$ for natural fluorrapatite and (0.46) for activated fluorapatite (Table-2) indicates that adsorption is favorable. 


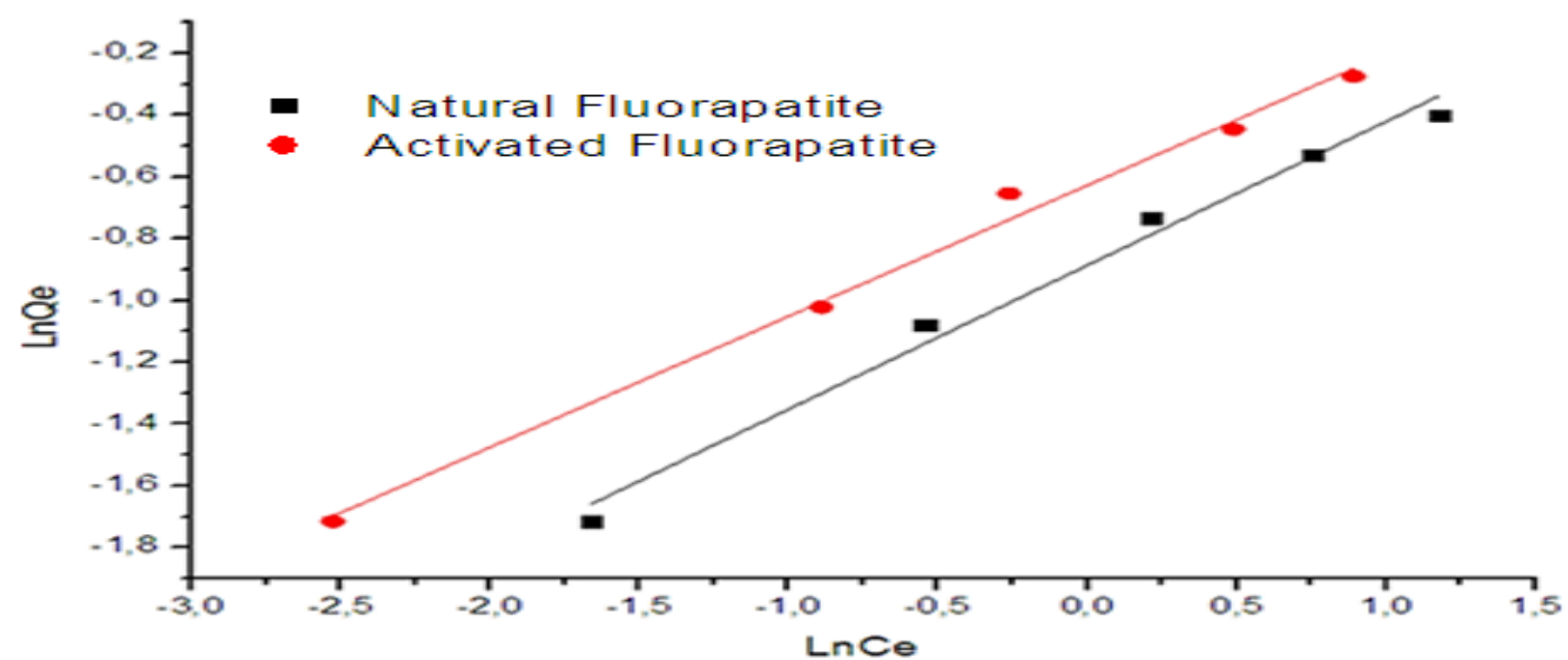

Fig. - 8: Linear Representations of the Freundlich Model for the Adsorption of Cr (VI) ion Natural and Activated Phosphate.

Table-2: Constants of the Langmuir and Freundlich models.

\begin{tabular}{l|c|c|c|c|c|c|c}
\hline & \multicolumn{4}{|c|}{ Langmuir model } & \multicolumn{3}{c}{ Freundlich model } \\
\hline \multicolumn{1}{c|}{ Parameter } & $\mathrm{q}_{\max }(\mathrm{mg} / \mathrm{g})$ & $\mathrm{K}_{\mathrm{L}}(\mathrm{L} / \mathrm{mg})$ & $\mathrm{R}^{2}$ & $\mathrm{R}_{\mathrm{L}}$ & $\mathrm{K}_{\mathrm{F}}(\mathrm{L} / \mathrm{g})$ & $1 / \mathrm{n}$ & $\mathrm{R}^{2}$ \\
\hline Natural Fluorapatite & 0.82 & 1.28 & 0.99 & 0.07 & 1.86 & 0.41 & 0.99 \\
\hline Activated Fluorapatite & 0.87 & 2.17 & 0.98 & 0.05 & 2.43 & 0.46 & 0.99 \\
\hline
\end{tabular}

\section{CONCLUSION}

In this work, we study the effect of different parameters on the removal of chromium (VI) by adsorption on crude and activated phosphate. The tests carried out in synthetic solutions of chromium. From all the results obtained. It concluded that:

- The study of kinetic adsorption of Chromium (VI) on raw and Activated Flourapatite shows that the adsorption process is rapid and the maximum adsorbed amount of Chromium (VI) they reached in 40 minutes. Chromium (VI) removal efficiency, they improved with an increasing dose of adsorbent.

- Removal of chromium (VI) by adsorption on crude and active phosphates is more effective in water with low chromium concentration (VI). Because the effectiveness of treatment decreases with the increase in the initial concentration of chromium (2 to $10 \mathrm{mg} / \mathrm{l})$.

- The absorption of chromium (VI) influenced by the $\mathrm{pH}$ for both adsorbents; the best yields we obtained in acidic media

- The kinetic models of Langmuir and Freundlich correctly described the adsorption process.

\section{ACKNOWLEDGMENT}

The authors gratefully thank Chemistry Department. Faculty of Sciences. The University of Chouaib Doukkali.

\section{REFERENCES}

1. T. Karthikeyan et al., Journal of Hazardous Materials, B124, 192(2005), DOI:10.1016/j.jhazmat.2005.05.003

2. Y.A. Aydın, N. D. Aksoy, Chemical Engineering Journal, 151, 188(2009), DOI:10.1016/j.cej.2009.02.010

3. L. Arab, M. Boutahala, B. Djellouli, Comptes. Rendus. Chimie., 17,860(2014), DOI:10.1016/j.crci.2014.01.013

4. W. Fang, X. Jiang, H. Luo, J. Geng, Chemosphere, 197, 594(2018), DOI: 10.1016/j.chemosphere.2017.12.163 
RASĀYAN J. Chem.

Vol. 12 | No. 1 |347 - 354| January - March | 2019

5. L. Guocheng, L. Zhaohui, J. Wei, The Chemical Engineering Research and Design, 92, 384(2014), DOI: $10.1016 /$ j.cherd.2013.08.003

6. L. Khezami, R. Capart , Journal of Hazardous Materials, B123,223(2005), DOI:10.1016/j.jhazmat.2005.04.012

7. F. Tadjik, O. Mirzaee and H. Ebrahimzadeh, Indian Journal of Science and Technology, 8(13) (2015), DOI: $10.17485 / \mathrm{ijst} / 215 / \mathrm{v} 8 \mathrm{i} 13 / 73217$

8. Y. Hanumantha Rao, and K. Ravindhranath, Rasayan J. Chem., 10(4), 110(2017), DOI: 10.7324/RJC.2017.1041829

9. A. Yantus, B. Neolaka, B. Eka, S. Kalla, G. Supriyanto, N. Puspaningsih, Rasayan J.Chem.,10(2), 606(2017), DOI: 10.7324/RJC.2017.1021710

10. A. K. Wanjari and U. E. Chaudhari, Rasayan J. Chem., 10(1), 82(2017), DOI: 10.7324/RJC.2017.1011556

11. A. Aklil , M. Mouflih, S. Sebti, Journal of Hazardous Materials, 112,183(2004), DOI:10.1016/j.jhazmat.2004.05.018

12. M. Mouflih, A. Aklil, S. Sebti, Journal of Hazardous Materials, B119,183(2005) DOI:10.1016/j.jhazmat.2004.12.005

13. Z. Elouear et al., Journal of Hazardous Materials, 156, 412(2008), DOI: 10.1016/j.jhazmat.2007.12.036

14. G.N. Kousalya et al., Adsorption Science \& Technology, 28(1), 49( 2010), DOI: 201010.1260/02636174.28.1.49

15. Y. Neolaka, E. Kalla, G. Supriyanto, Suyanto, N. Tri Puspaningsih, Rasayan J. Chem., 10(2), 606(2017), DOI: $10.7324 /$ RJC.2017.1021710

16. A. M. Aljeboree, A. N. Alshirifi, A. F. Alkaim, Arabian Journal of Chemistry, 10, S3381(2017) DOI:10.1016/j.arabjc.2014.01.020

17. H. M. F. Freundlich, J. Phys. Chem., 57, 385 (1906), DOI: 10.1515/zpch-1907-5723

[RJC-5078/2018] 